\title{
REMEMBERED, READ AND EXPERIENCED TIME IN VIRTUAL TEXT
}

\author{
Raine Koskimaa*
}

\begin{abstract}
In this article I will scrutinize Screen (2002, by WARDRIP-FRUIN \& al.), a literary work set and experienced in a CAVE Virtual Reality environment, especially from the perspective of its temporal aspects. There are obvious themes of remembering, forgetting and textually constructing the past in this work, but most notably, Screen emphasizes the temporality of the reading act itself. I will analyze this highly special work in relation to the remembered, read, and bodily experienced time, and thus, attempt to better understand both the notion of fictive time and the temporality of fiction.
\end{abstract}

KEYWORDS: Fictional time. CAVE. Screen. Virtual reality. Virtual text.

\section{Introduction}

In narrative texts, there are always several temporal layers juxtaposed. Most notably, there is a temporal distance between the instance of narration, and the narrated events. Narratology has provided detailed accounts of the temporalities within the narrative structure, but the question of reading time, the time a person spends reading certain text falls outside the scope of narratology, nor has there been too many attempts to conceptualize reading time in other schools of literary research either.

It is relatively easy to dismiss the relevance of reading time in respect to traditional narrative texts. The case, however, is wholly different with digital literature where the texts may be programmed to behave in various ways, which require the reader to react to the changes on-screen within the time-constraints provided by the dynamic text. The texts themselves becoming dynamic, transforming entities complicates the textual temporality in many ways, and understanding this novel textuality is only gradually developing (cf. WARDRIP-FRUIN, 2009; ESKELINEN, 2012).

\footnotetext{
* Department of Art and Culture Studies, University of Jyväskylä, Finland and Hermeneia Research Group. E-mail: raine.koskimaa@jyu.fi
}

\section{(cc) BY-NC-ND}

Esta obra está licenciada com uma Licença Creative Commons. 


\section{Understanding Fictional Time}

Repeatedly it has been pointed out that the exceptional quality of digital fictions lie in their inherently dynamic nature, how they may be flexibly programmed to generate new content and alter the already existing contents. This adds a new temporal level, compared to traditional fictions. Already the history of digital fictions presents us with a variety of temporal practices, even though this dimension has not been thoroughly discussed so far. One of the classic hypertext novels, Michael Joyce's Afternoon (1987), employs conditional links, with the effect of temporally postponing the accessibility of certain parts of the hypertext. Stuart Moulthrop's Hegirascope (1995) is a 'textual cinema', where each page possesses a measurable true time duration. Reagan Library (1999), also by Moulthrop, varies the amount (or length) of text in a node relative to the reading time: if you re-read certain node, its contents have been extended.

In computer games, part of which, so-called ludo-narrative games (AARSETH, 2012), also belong to the field of digital fictions, this sort of real-time dynamics is routinely taking place. Thus, in the existing digital fictions we have examples of ways to manipulate the relation between story time (the time of events told) and discourse time (the time of narration) which challenge the conventional ways of understanding fictional time.

In classic narratology (eg. GENETTE, 1980) time in narrative fiction was studied in three dimensions: order, frequency and speed. Order deals with both the order of the events as they happened, and as they are narrated (the point of departure here is that events may be told in the same order as they happened, or, in a different order). With frequency the situation is very much the same: the events may be told as many times as they happened or different amount of times (a single event may be told twice, for example). The speed is very different phenomenon, however, since there is no proper way to quantify speed in textual narrative. Instead, we have to rely on certain conventions providing us with the framework of pseudo time (time measured spatially, by the amount of text used to describe a passage). Thus, if the events of a 
life time are recounted in a few pages, we have the feeling that narration is speeded up, that the discourse proceeds faster than the events. Or in another direction, if some simple event is recounted using several pages, we have the feeling that the discourse is proceeding slower than the events. Somewhere in between, there is the balance where the discourse and the story seem to proceed at approximately the same pace.

All this applies to digital fictions as well, but in addition to the pseudo time we also need to take into account the measurable true time. Thus, we have at least the following four temporal levels for digital fictions with narrative content:

1. user time (the time the user spends reading the work)

2. discourse time (the time of the narrative discourse)

-pseudo time (of textual narration)

-true time (of the behavior on screen)

3. story time (the time of the fictional events)

4. system time (the time of the digital system states) ${ }^{1}$

All this is largely not covered by research yet (game studies being somewhat of an exception). What more, paying attention to the measurable true time leads way to the realization that narrative time altogether is badly neglected in research. Investigating the temporality of digital fictions necessarily entails a critical re-examination of our notions of fictional time.

\section{Screen: Fiction in Virtual Reality}

There is a particular class of digital fictions, installed in immersive Virtual Reality environments known as CAVEs. With CAVE works, there is one more added element, to be accounted for, that is the bodily experience of the reading act, as these works require the reader to physically move inside the three-dimensional textual landscape. The interest in this paper lies in how the fictional structuring of the

\footnotetext{
${ }^{1}$ The system time falls out of the scope of this article. I have discussed system time in eg. KOSKIMAA 2011.
}

Texto Digital, Florianópolis, Santa Catarina, Brasil, v. 11, n. 1, p. 250-262, jan./jun. 2015. ISSNe: 1807-9288. 
time within the text, the reading time, and the bodily experience of the work relate to each other in Screen (2002) by Noah Wardrip-Fruin (with Josh Carroll, Robert Coover, Shawn Greenlee, Andrew McClain, and Ben Shine; on CAVE as a writing environment see CAYLEY, 2005).

Screen has been made for the CAVE virtual reality environment at the Brown University. In this CAVE three walls and the floor function as displays and create a virtual space within which the user physically moves with goggles on her eys and a pointer in her hand. This article is based on various encounters with the work in 2005, 2009, 2010 and 2011 (the Brown University CAVE has been rebuilt after the last visit, and the specifications given here do not hold with the current setting) ${ }^{2}$. Screen begins with a scene, where text passages gradually fill the walls, with voiceover recitation, so that eventually the reader is surrounded by three stable (for a certain period) text walls (see Figure 1.)

Fig. 1 - Screen, soon after the words have started to peel off the wall.

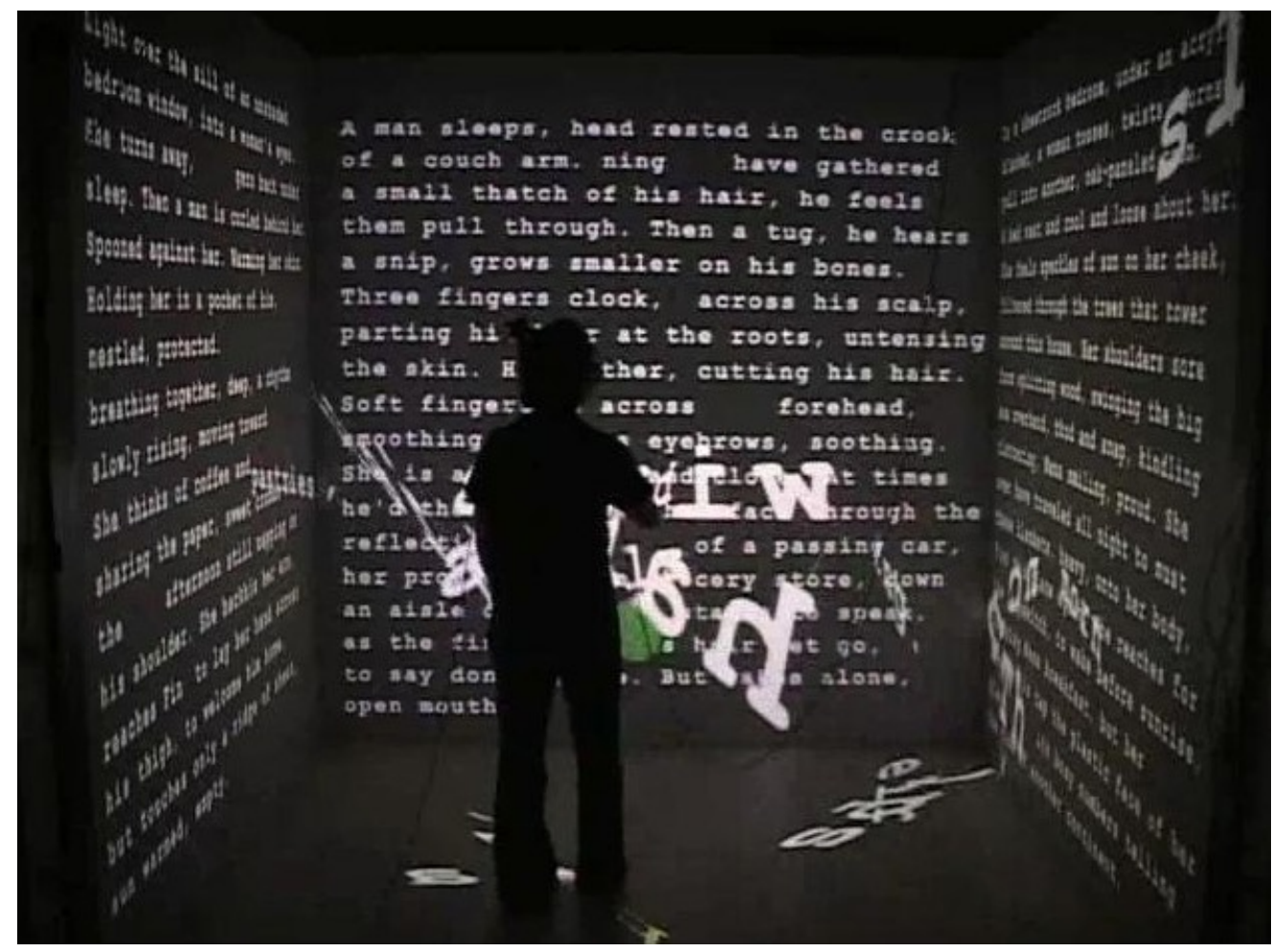

\footnotetext{
${ }^{2}$ In addition to the first hand experiences, this article is also taking advantage of the video recording of the Screen available at: <https://www.youtube.com/watch?v=dSLChcV_a3o>.
}

Texto Digital, Florianópolis, Santa Catarina, Brasil, v. 11, n. 1, p. 250-262, jan./jun. 2015. ISSNe: 1807-9288. 
After a while, individual words start peeling loose from the walls and fly circulating in the air, prompting a word by word reading. In addition to reading, the user can also knock the words back to their places on the wall using the pointer in her hand. This adds an element of play into the experience. The speed of the words peeling off gradually increases, and eventually it will be impossible to knock them all back to the walls. (see Figure 2.) This creates an ever densening, rotating mass of text in the center of the space, where no individual words are fully legible anymore. Some of the words knocked back to walls will not return to their original place, but to another vacant position. Thus, also the text on the wall starts to syntactically and semantically deteriorate. Finally, all of the text collapses in the center of the cave, rendering it into a totally unreadable "white hole". (see Figure 3)

Figure 2. Words peeling off the wall.

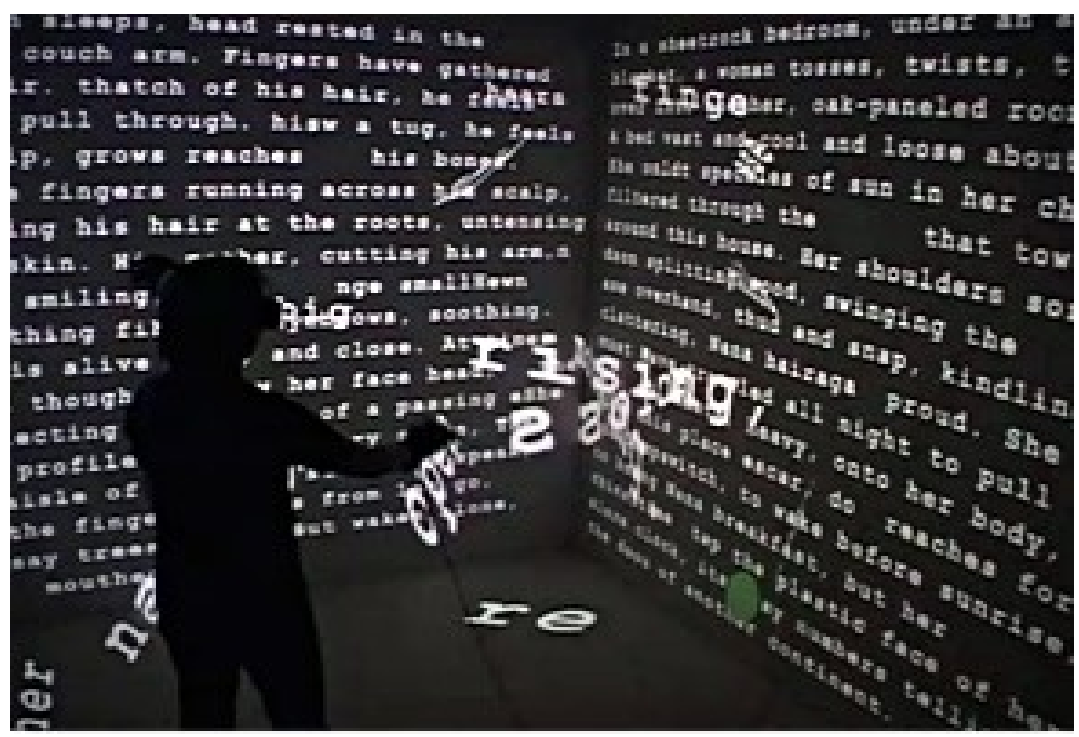


Fig. 3 - The collapse of the text walls.

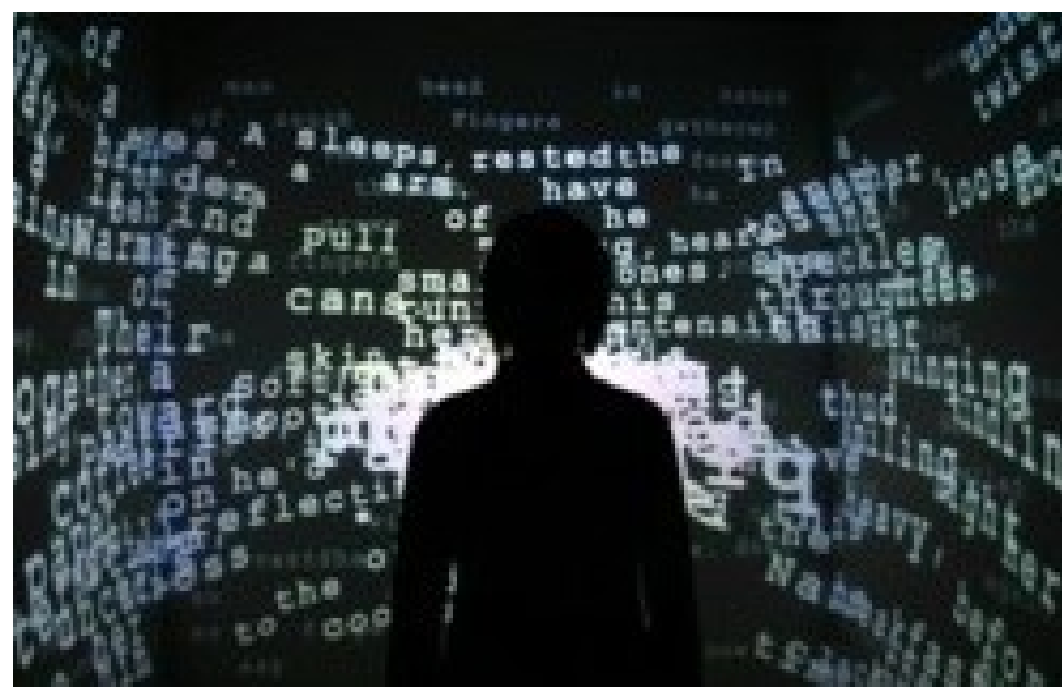

\section{Reading Screen}

The work combines three ways of reading. First, there is the traditional reading of stable text in the opening passage. Even here, the text appears gradually and accompanied by the voice-over, so there is a light temporal constraint upon the reading. Second, there is the reading of moving words when they start to peel off the walls and the accompanying (and optional) hitting of them with the pointer device. The uncanny feeling of 'touching' words creates a specific sense of estrangement, and the movement of words and the related attempt to hit them brings also a strong sense of play, even a fight, into the work. The play is ambiguous, though, as playing faster and 'better' prolongs the experience and initially creates a sense of success, but, the longer the play - and reading - lasts, the more disordered the memory text becomes, as the words hit do not usually return to their original places, but to any vacant positions.

The reader may only prolong the experience to an extent, in a highly physical act of moving around the cubicle of the CAVE, trying to find suitable positions to both hit the words and to have best possible angle to read them. Eventually, there is no way to avoid the word-walls collapsing to an illegible 'white hole and the reader cannot but try and dodge the final crash. 
All this physical playing activity combined with the more conventional reading as deciphering textual messages forms an exemplary case of what Espen Aarseth has termed 'ergodic reading' where 'non-trivial effort' is required from the reader (1997, p. 1-2).

\section{Time as Theme in Screen}

In the fictive text of Screen, there are apparent themes of remembering, forgetting and textually constructing the past:

Three fingers running across his scalp, parting his hair at the roots, untensing the skin. His mother, cutting his hair. [...] She is alive then and close. fearful of losing our very selves if we lose the stories of ourselves

The opening passage's musings about the nature of memories and their importance for our identity-building are highly metafictional in how they anticipate what is going to happen in the work:

\footnotetext{
In a world of illusions, we hold ourselves in place by memories.

These musings may even be read as a kind of manual for Screen, advising what to reader is supposed to do when the texts, actually, start peeling away.

The three walls contain each a passage, one telling about a woman, one about a man, and one about a woman and a man together. It is quite obvious assumption, that it is the same man and woman in each passage. One interpretation would be that the story is about how the woman and man, after a break-up, are each sleeping 
alone and remembering their time together (among other reminiscents). Both the passage telling about the woman (and narrated by a female voice over) and the man (with male voice over) relate a moment of waking up, the evanescent moment of dream and reality merging. The ephemeral nature of this moment is juxtaposed with the nature of memories, how illusory and incomplete memories are. The fabric of memories is as thin as dreams, and still they constitute the basis of our very identities. There is an almost painful realization of the fundamental ontological fact that the past is only accessible indirectly through artefacts like photographs and mental constructions like stories. The recurring descriptions of reality and dream merging and past and present merging are also reflected in the narrative situation, where the past comes alive through a narrating act in the present.

There is also a passage in the text, which refers to the various time zones.

She reaches for the lampswitch, to wake before sunrise, to bring Nana breakfast, but her fingernails tap the plastic face of her alarm clock, its boxy numbers telling the time of another continent.

Here, again, we are witnessing the fusion of two temporal levels, this time two time zones being confused in the person's head. Reference to the geographical time differences reminds us of the situation where some things happening 'at the same' in various parts of the globe actually happen at different clock measures, that we are constantly inhabiting just one of the several parallel time zones. The time zones themselves are just handy fictions, or contracts, to avoid the mess of each Meridian having its own time (the 'true time' based on Earth's movement around the Sun).

\section{Experiencing Screen}

The textual space of Screen, in one way, resembles a letterized planetarium where the relative motions of both the gazer and the gazed are intertwined. It can be the reader who is moving around the word objects, or, from other perspective, the word universe moving around the reader. In the CAVE setting, this equals to the screen contents being opaque (subject for gazing from various angles) or transparent 
(windows to fictional universe rotating in its complex way around the reader). The psychological confusion of different temporalities is complemented here with the CAVE style of physical relativity of time, where the change of vantage point causes the temporal indicators to change accordingly (between the discourse time and the reading time).

It is here that the temporal aspect of the reading act itself becomes significant. The movement of the words in the CAVE space places a constraint on the reading so that the time spent reading certain word or passage counts in a concrete way. The decision to spend time reading something is always a decision also not to do something else with that time. To some extent, it may be possible to do more than one thing (reading) at a time, as when the reader is also aiming at the words with the pointer and bouncing them back to the wall while reading the same word or some other words begging for attention too. When reading narrative fiction, we are not only spending time in reading and parsing a text, but we are also spending time in the make-believe fictional world. Usually, there is quite a clear division between these two activities, in that the mental experience of fictional time may be wholly distinct from the time spent reading the constitutive text -- this is often referred to as "losing the sense of time" when immersed in fiction. The real time spent in reading usually seems not to bear any relevance to the fictional time, but digital fictions like Screen do not allow such division. The real reading time is constantly foregrounded through active, bodily engagement with the textual world, very much like in playing digital games.

The situatiation where the reader is constantly aware of the reading experience itself, may result in two alternative constellations:

1. there are three temporal levels of the fictional past, fictional present, and reader's present simultaneously at play and the reader shifts between these levels according to her individual reading strategy

2. there is only one temporal level experienced, that is, all formal levels collapse to the present of the reading. 
Referring to Henri Bergson's categories of measurable time and experienced duration, it seems that duration is primarily related to the bodily engagement of the reading, and with Screen, the bodily experience of duration is dominating the temporal ordering. (cf. BERGSON, 2002) While experiencing the work, we are not able to fully grasp the discoursive levels, but it is rather the act of narrativizing the experience retrospectively when we can make such nuanced divisions.

Seen from the physics perspective, time is a fundamental property of the reality, alongside the spatiality, hence the concept of space-time. There is a property of physical time, which is interesting for this investigation, that is, time is irreversible, it only flows in one direction, towards the increase of entropy (even though locally the process may be slowed down, stopped, or possibly even turned backwards, for a certain period).

Psychologically, or phenomenologically, we are dealing with the issue of how we, as humans, perceive and experience time. What is common between physical and psychological time is the notion of irreversibility of time: things once done cannot be undone. Psychologically time is naturally tied to change, we experience time as changes in our selves or in the world around us. Even though we constantly witness the decay of material world around us, we do not necessarily make such a tight connection to entropy as within the physical framework. In spite of the material decay, it is possible also to perceive the temporal change as a process of fulfillment and development towards perfectness. This is based on the division between material and immaterial world, be the immaterial world either religious-spiritualmystical, or, ethico-aesthetical realm where perfection is sought after.

For Bergson the duration is something qualitative, simultaneously a multiplicity and a unity. It can only be grasped through intuition. In Screen, as in most of digital games, we are facing the constant balancing and tension between chaos and order, movement towards order or entropy. The fragmentation and disappearance of memories is presented not only in the content of the narrative discourse, but also in 
its form. In a way of dream-logic the deterioration of memories is taken out of the sphere of intuition, and made visible and (virtually, at least) touchable. The yearning for the time when everything was perfect (or, at least as good as it in a human life can get) is juxtaposed with the irresistible enthropy both in the physical world and our mental constructions and in this sense, Screen presents a highly pessimistic, even gloomy view of our existence.

\section{Entropy and Closure}

Simply put, Screen is placing us in a situation, where we are very concretely fighting against time and forgetting. Time and forgetting here serve to instantiate the physical phenomena of decay and entropy. From our everyday life, we can recognize this struggle in the occasional experiences of the liminal state right after waking up, when the dream is quickly vanishing from the memory and are desperately trying to hold on to the dream before it fully evaporates.

Compared to phenomena such as the Universe, life, or, dream, Screen differs in one main aspect, which is its nature as a deterministic system. As such, it is able to bring along a closure to the process. The closure serves to end the bodily engagement with work, whereas the memories, in their incompleteness remain with us for a longer or shorter period (in my own case, I can still vividly recall the very first encounter with Screen, and especially the closing passage, after nine years).

The work ends in chaos, where the sentences and words lose their legible content, and they become one undifferentiated mass. This is as close as we can get to experiencing the 'end of time'. The price for having the privilege of that rare experience is that the reader has to 'step out of time', the split between real time and fictional time becoming apparent as the fictional world collapses leaving the reader stand outside. It is possible to position oneself in the CAVE in such a way that the vantage point is inside the 'white hole' but even there the time stands still as there is no change anymore. 
The narrativization of the experience, as in this article, starts after the closure, but the stories we (I) tell after the fact are based on diminishing memories. The bodily experience is quite important in how it imposes a strengthened level of embodied remembrance. There is the remembered feeling of how it was to touch the words, to feel the shock when the walls started to fall on you, and the feel of stepping outside of the textual universe.

Altogether, Screen is a specific instance of digital fiction, combining the flexibility and preciseness of digital simulations, with psychologically engaging narrative qualities. Even though the CAVE environment is pointedly spatial, it serves well the inquiry of temporal issues as well. The bodily engagement with the work emphasizes the experienced duration of the events, a feature which clearly differentiates digital fictions from the traditional narratives, where instead of Bergsonian duration, the measured time as accounted by the narrator prevails. This quality makes the temporal reflections in Screen so powerful.

\section{TEMPO LEMBRADO, LIDO E EXPERIENCIADO NO TEXTO VIRTUAL}

RESUMO: Neste artigo vou examinar Screen (2002, por Wardrip-Fruin \& al.), uma obra literária experimentada em um ambiente de realidade virtual (CAVE), especialmente a partir da perspectiva de seus aspectos temporais. Há temas óbvios de lembrar, esquecer e textualmente de construção do passado no presente trabalho, mas mais notavelmente, Screen enfatiza a temporalidade do próprio ato de leitura. Vou analisar esse trabalho em relação ao tempo lembrado, lido e experimentado corporalmente e, portanto, vou tentar compreender melhor tanto a noção de "tempo fictício" quanto a temporalidade da ficção.

PALAVRAS-CHAVE: Tempo. Cave. Screen. Realidade virtual. Texto virtual ficcional.

\section{References}

AARSETH, Espen. Cybertext. Perspectives on Ergodic Literature. Baltimore, MD: Johns Hopkins University Press, 1997.

AARSETH, Espen. A Narrative Theory of Games. Proceedings of the International Conference on the Foundations of Digital Games - FDG'12G'12, p. 129-133. New York, NY: ACM Press, 2012. 
BERGSON, Henri. Key Writings. London, England \& New York, NY: Continuum, 2002.

CAYLEY, John. Writing on Complex Surfaces. Dichtung Digital, v. 7, n. 2, 2005. Last access October 30, 2014. URL: <http://www.dichtung-

digital.org/2005/2/Cayley/>.

ESKELINEN, Markku. Cybertext Poetics. The Critical Landscape of New Media Literary Theory. London, England \& New York, NY: Continuum, 2012.

GENETTE, Gerard. Narrative Discourse. An Essay in Method. Ithaca, NY: Cornell University Press, 1980.

JOYCE, Michael (1987). Afternoon. A Story. Watertown, MA: Eastgate Systems, 1987.

KOSKIMAA, Raine. "Changing the Past: Time-reversal as Game Mechanic". Media in Transition MIT7 Conference Proceedings. Last accessed October 30, 2014. URL: <http://web.mit.edu/commforum/mit7/papers/MIT7_Paper_Koskimaa_08_05_11.pdf>.

MOULTHROP, Stuart. Hegirascope. The New River, n. 3, 1997. Last accessed October 30, 2014. URL:

<http://www.cddc.vt.edu/journals/newriver/moulthrop/HGS2/Hegirascope.html>.

MOULTHROP, Stuart. Reagan Library. Stuart Moulthrop's personal webpage, 1998. Last accessed October 30, 2014. URL:

<http://pantherfile.uwm.edu/moulthro/hypertexts/rlx/>.

WARDRIP-FRUIN, Noah. Expressive Processing. Digital Fictions, Computer Games, and Software Studies. Cambridge, MA \& London, England: The MIT Press, 2009.

WARDRIP-FRUIN, Noah \& al. (2002). Screen. A Virtual Reality installation at the Brown University CAVE environment. 